\title{
Bernard LACROIX, Xavier LANDRIN, Anne-Marie PAILHES et Caroline ROLLAND-DIAMOND (dir.), Les Contre-Cultures. Genèses, circulations, pratiques
}

\section{Blaise Magnin}

\section{(2) OpenEdition}

\section{Journals}

Édition électronique

URL : http://journals.openedition.org/ress/3555

DOI : $10.4000 /$ ress.3555

ISBN : 1663-4446

ISSN : $1663-4446$

\section{Éditeur}

Librairie Droz

\section{Édition imprimée}

Date de publication : 30 novembre 2016

Pagination : 310-313

ISSN : 0048-8046

Référence électronique

Blaise Magnin, «Bernard LACROIX, Xavier LANDRIN, Anne-Marie PAILHES et Caroline ROLLANDDIAMOND (dir.), Les Contre-Cultures. Genèses, circulations, pratiques », Revue européenne des sciences sociales [En ligne], 54-2 | 2016, mis en ligne le 28 juillet 2016, consulté le 25 septembre 2020. URL : http://journals.openedition.org/ress/3555; DOI : https://doi.org/10.4000/ress.3555

Ce document a été généré automatiquement le 25 septembre 2020.

(c) Librairie Droz 


\title{
Bernard LACROIX, Xavier LANDRIN, Anne-Marie PAILHES et Caroline ROLLAND-DIAMOND (dir.), Les Contre-Cultures. Genèses, circulations, pratiques
}

\author{
Blaise Magnin
}

\section{RÉFÉRENCE}

Bernard LACROIX, Xavier LANDRIN, Anne-Marie PAILHES, Caroline ROLLAND-DIAMOND (dir.), 2015, Les Contre-Cultures. Genèses, circulations, pratiques, Paris, Syllepse, « La politique au scalpel », $526 \mathrm{p}$.

1 Issues d'un colloque international et pluridisciplinaire qui s'est tenu en 2012 à l'université Paris-X-Nanterre, les contributions rassemblées dans ce volume proposent un parcours raisonné à travers les contre-cultures, en même temps qu'un tableau évocateur de la diversité et de la vitalité des investigations dont elles font l'objet. Au croisement de l'histoire sociale des formes protestataires, des cultural studies et de l'analyse des circulations et des transferts culturels, l'ouvrage questionne tout à la fois les conditions sociales d'émergence de la contre-culture, la constitution d'un répertoire contestataire multiforme au gré de ses circulations et de ses appropriations nationales et transnationales, et les enjeux que recouvrent ses reformulations successives.

2 L'introduction, qui présente un bilan problématisé des recherches sur les contrecultures, fait également office de cadrage théorique et méthodologique. En insistant sur l'historicité des phénomènes contre-culturels, Bernard Lacroix, Xavier Landrin, AnneMarie Pailhès et Caroline Rolland-Diamond rappellent que le qualificatif de "contreculture » est une "catégorie indigène ", forgée par celles et ceux qui sont en même 
temps des acteurs et des observateurs des pratiques contestataires et alternatives qui se développent dans les années 1960-1970. Les auteurs invitent dès lors à rompre avec les définitions essentialisantes et les généalogies réifiantes qui réduisent la contreculture à quelques images et références stéréotypées et empreintes de folklore; de la même façon, ils invitent à remettre en cause les illusions rétrospectives enchantées, comme les reconstructions interprétatives disqualifiantes qui hantent l'histoire et les analyses de ce moment et de ces mouvements contestataires.

3 Par ailleurs, cette introduction montre qu'on ne saurait objectiver l'émergence, le développement ainsi que la circulation internationale des contre-cultures sans revenir sur leurs conditions sociales de possibilité - et donc sur les propriétés structurelles et les configurations conjoncturelles dans lesquelles elles se déploient. Entre 1965 et 1974, avec le foisonnement d'organisations militantes nouvelles, d'initiatives et de mobilisations protestataires, de festivals et de rassemblements, d'expériences et d'œuvres emblématiques apparaissent les manifestations d'une désaffiliation culturelle de certaines franges des classes moyennes, mais aussi de membres des classes ouvrières émancipés, notamment, par l'accès à l'enseignement supérieur dont ils font un usage critique. Toutefois, au-delà d'une vague protestation généreuse, il n'y a guère d'unité en tant que telle de la contre-culture.

4 Dans cette perspective, les auteurs proposent une hypothèse particulièrement stimulante et heuristique: dans le contexte français, l'émergence de dispositions contestataires, d'un style contre-culturel et d'aspirations utopiques, qui sont au cœur des " années 68 ", paraît indissociable de l'évolution des rapports à un univers scolaire connaissant de profondes transformations - et notamment un accroissement rapide des effectifs. À cet égard, la synchronisation internationale des luttes étudiantes pourrait bien n'être qu'un artefact trop apparent, bien qu'elle renvoie pourtant au Mexique, en Italie ou au Japon, par exemple, à des configurations et des conditions de possibilité homologues au cas français.

5 La première partie de l'ouvrage ("La construction d'un "texte" contre-culturel ») a trait non seulement aux processus de consécration de figures et d'auteurs tenus pour emblématiques, mais aussi aux différents supports imprimés par lesquels ils circulent. La centralité et l'antériorité de la référence états-unienne est mise en exergue par l'étude de l'apparition au sein des avant-gardes intellectuelles et artistiques newyorkaises et californiennes de figures rétrospectivement présentées comme fondatrices, telles Wallace Berman, personnalité éminente de la beat generation, ou Susan Sontag. L'étude des appropriations du marxisme hétérodoxe d'Herbert Marcuse et d'Henri Lefebvre (Matthieu Rémy), d'une part, l'analyse de la diversité des usages de la référence situationniste, en France, puis au cours de sa large circulation internationale (Anna Trespeuch-Berthelot), d'autre part, apportent ensuite des éclairages utiles sur le processus de constitution d'un corpus de référents théoriques contre-culturels. Enfin, plusieurs contributions mettent en évidence le rôle de la presse alternative dans la mise en cohérence et en relations de références et de pratiques hétérogènes, gardant toutefois une esthétique avant-gardiste en commun, et des positions marquées par une certaine radicalité critique.

6 La deuxième partie («Les transformations du répertoire contestataire ») présente un riche panorama des formes de protestation et de leurs évolutions depuis les années 1960, elles-mêmes indissociables de leur dimension transnationale; elle permet de souligner la variété des ressorts, des thématiques et des cibles de la critique (politique, 
sociale, artistique, de genre). Le caractère protéiforme des mobilisations et des pratiques contre-culturelles, leur capacité à investir et subvertir les scènes sociales les plus diverses, et leur rôle dans la construction d'identités indissociablement militantes et genrées, ou sexuelles, apparaissent nettement dans des contributions touchant à l'interpénétration des activités théâtrales et politiques dans le Berlin de la fin des années 1960 (Charlotte Bomy), à la mobilisation de groupes de femmes s'élevant contre l'association systématique de schèmes sexistes au thème de la libération sexuelle dans les fanzines américains du début des années 1970 (Beth Bailey), ou encore aux usages distanciés et critiques de l'élection par des militants homosexuels présentant des candidats, à la toute fin des années 1970, en France (Antoine Idier). Par ailleurs, la question des tensions entre engagement sur la scène politique institutionnelle et mobilisation contre-culturelle, et plus généralement des relations entre champ politique et mouvements contestataires, traverse plus ou moins directement l'ensemble des contributions de cette partie, et notamment celle de Michaël Rolland. Cette dernière revient sur la complexité des relations entre "gauchismes" et contrecultures, faites à la fois de porosité et de dissensions.

7 Une troisième partie («Lutter dans et en dehors de l'institution») prolonge sous plusieurs rapports la précédente. En interrogeant les devenirs militants, d'abord; en questionnant ensuite l'articulation souvent conflictuelle et ambiguë entre investissements contre-culturels, construction d'alternatives émancipatrices, et la prégnance d'un ordre institutionnel qui tend sans cesse à les rattraper - avec des résultats et des conséquences qui varient en fonction de l'évolution des configurations dans lesquelles sont prises institutions et pratiques concernées. C'est ainsi que les courants qui cherchèrent à affirmer une contre-culture critique et contestataire dans l'Église catholique française, formèrent au tournant des années 1970 une mouvance aussi variée que dynamique, avant de décliner inexorablement dans la décennie suivante. L'épuisement militant se nourrit alors de la position en porte-à-faux de ses membres, à la fois dans et hors de l'institution, impliqués simultanément sur les terrains religieux et politique (Vincent Soulage). Dans un tout autre ordre d'activité, si le mouvement néo-rural français et les pratiques agricoles alternatives qu'il contribue à développer au cours des années 1960 et 1970, en France, semblent initialement indissociables d'une contestation du productivisme et du modèle économique dominant, Benoît Leroux montre que le processus d'institutionnalisation marchande dans lequel s'est engagée l'agrobiologie depuis les années 1980 s'accompagne d'un abandon progressif de son héritage critique. Un tel reflux des postures contestataires ne semble pourtant pas inexorable, ainsi que le montre Eric Doidy qui expose la trajectoire d'un acteur des mouvements américains de « retour à la terre » des années 1970, reconverti dans une carrière d'entrepreneur du marché de l'agriculture biologique, et qui mobilise et réinvestit son capital militant et professionnel en faveur des mouvements de protestation contre les guerres états-uniennes en Irak et en Afghanistan dans les années 2000.

8 La dernière partie, intitulée "Genèse et circulation des contre-cultures musicales ", fait encore apparaitre en filigrane cette question des rapports et des tensions entre activités contre-culturelles et culture, ou institutions dominantes. Christophe Voilliot montre ainsi que la labellisation contre-culturelle du free jazz en France, comme style à la fois avant-gardiste et subversif, repose paradoxalement sur le travail de promotion commerciale et les investissements d'ampleur de la maison de disques BYG. La trajectoire du mouvement punk, présentée par Romuald Jamet, est toute autre, mais on 
y perçoit également comment le slogan "Do it yourself» a pu demeurer chez les musiciens amateurs le support d'un radicalisme esthétique et contestataire, alors même que la musique punk abandonnait l'essentiel de sa portée critique à mesure qu'elle intégrait l'industrie musicale dans les années 1980 et 1990.

9 En conclusion, David Farber revient sur le foisonnement de communautés qui ont émergé au États-Unis à la fin des années 1960, et notamment sur leurs tentatives d'inventer des «modes de vie justes » reposant sur des pratiques économiques inédites et tâtonnantes et visant moins une quelconque autarcie que la construction d'alternatives durables. À travers les multiples expériences qu'il présente, sans en escamoter les difficultés, les apories et parfois les échecs, on prend la mesure du caractère artificiel des oppositions authentique/commercial, underground/ mainstream, critique/récupération, etc. dans lesquelles sont trop souvent enfermées les contre-cultures, et qui tendent à éluder la charge subversive de pratiques, de discours et d'aspirations - bref, d'entreprises politiques de rejet et de refus du mode vie dominant ainsi que de ses fondements économiques et politiques.

\section{AUTEURS}

\section{BLAISE MAGNIN}

Université Paris 10-Nanterre - GAP 